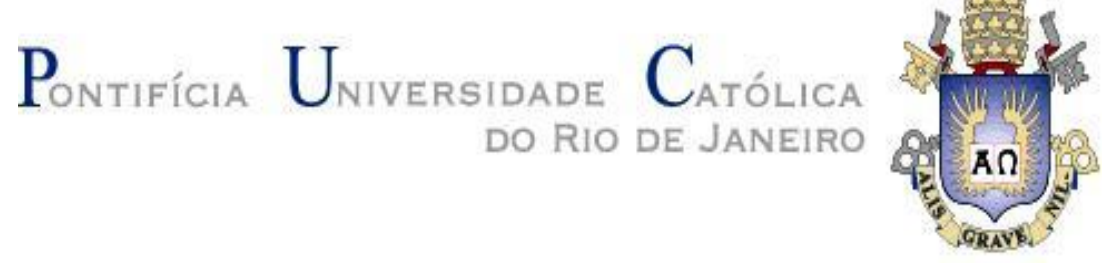

Luis Paulo Pires Gonçalves Ribeiro

\title{
Caracterização das Propriedades Mecânicas do Aço SAE 4140 após Diferentes Tratamentos de Têmpera e Revenido
}

Dissertação de Mestrado

Dissertação apresentada como requisito parcial para obtenção do título de Mestre pelo Programa de PósGraduação em Ciência dos Materiais e Metalurgia da PUC-Rio.

Orientador: Marcos Venicius Soares Pereira

Rio de Janeiro, 06 de setembro de 2006 


\title{
Pontifícia Universidade C atólica $_{\text {a }}$ \\ DO RIO DE JANEIRO
}

Luis Paulo Pires Gonçalves Ribeiro

\section{Caracterização das Propriedades Mecânicas do Aço SAE 4140 após Diferentes Tratamentos de Têmpera e Revenido}

\author{
Dissertação apresentada como requisito parcial para \\ obtenção do título de Mestre pelo Programa de Pós- \\ Graduação em Ciência dos Materiais e Metalurgia da \\ PUC-Rio. Aprovada pela Comissão Examinadora abaixo \\ assinada.
}

\section{Prof. Marcos Venicius Soares Pereira} Orientador Departamento de Ciência dos Materiais e Metalurgia - PUC Rio

Prof. Fathi Aref Ibrahim Darwish Universidade Federal Fluminense - UFF

Prof. Fernando Ribeiro da Silva Instituto Militar de Engenharia - IME

Prof. José Eugenio Leal Coordenador Setorial de Pós-Graduação do Centro Técnico Científico da PUC Rio

Rio de Janeiro, 06 de setembro de 2006 
Todos os direitos reservados. É proibida a reprodução total ou parcial do trabalho sem a autorização da universidade, do autor e do orientador.

\section{Luis Paulo Pires Gonçalves Ribeiro}

Aluno do Departamento de Ciência dos Materiais e Metalurgia da PUC-Rio entre os anos de 2004 e 2006. Graduou-se em Engenharia Metalúrgica pela UENF-RJ em setembro de 2003.

Ficha Catalográfica

\section{Ribeiro, Luis Paulo Pires Gonçalves}

Caracterização das Propriedades Mecânicas do Aço SAE 4140 após Diferentes Tratamentos de Têmpera e Revenido / Luis Paulo Pires Gonçalves Ribeiro ; orientador: Marcos Venicius Soares Pereira. - Rio de Janeiro: PUC-Rio, Departamento de Ciência dos Materiais e Metalurgia, 2006.

106 f. ;il. ; $30 \mathrm{~cm}$

Dissertação (mestrado) - Pontifícia Universidade Católica do Rio de Janeiro, Departamento de Ciência dos Materiais e Metalurgia.

Inclui bibliografia

1. Ciências dos Materiais e Metalurgia Teses. 2. Energia de impacto. 3. Fragilização no revenido. 4. Microestrutura. I. Pereira, Marcos Venicius Soares. II. Pontifícia Universidade Católica do Rio de Janeiro. Departamento de Ciência dos Materiais e Metalurgia. III. Título. 


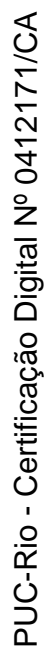

"Tudo posso naquele que me fortalece". 
A minha mãe e meu pai pelo apoio e estímulo e pela confiança em mim depositada.

A Tatiane Gabriele pelo apoio e palavras de carinho. A minha vó pela gratidão por tudo que fez durante estes anos.

A Deus meu grande companheiro durante esta jornada. 


\section{AGRADECIMENTOS}

Ao professor Marcos Venicius S. Pereira, pela orientação durante este trabalho.

Ao CNPq e à PUC-Rio, pelos auxílios concedidos, sem os quais este trabalho não poderia ter sido realizado.

Aos professores Fathi Darwish, Ivani Bott e Roberto Carvalho que muito contribuíram durante o curso de pós-graduação.

A metalúrgica MSteel pela doação do material e suporte financeiro para a realização do trabalho.

A BrasilAmarras pela cessão de suas instalações para a realização de algumas etapas experimentais desta pesquisa.

Ao Eng ${ }^{\circ}$. Sérgio Motta, gerente de tecnologia da BrasilAmarras, pela amizade e convivência durante a minha estadia na empresa.

A assistente Monique da BrasilAmarras pelo auxílio prestado durante a preparação e ensaio dos corpos de prova.

A todos os funcionários da BrasilAmarras, em especial a Antônio Balbino, meu muito obrigado.

Ao técnico Heitor Nuss do DCMM pelo auxílio prestado durante a preparação dos corpos de prova para o MEV e pela sua grande amizade.

Aos colegas de pós-graduação Percy e Fernando pela convivência durante estes anos. 


\section{RESUMO}

Ribeiro, Luis Paulo Pires Gonçalves. Caracterização das Propriedades Mecânicas do Aço SAE 4140 após Diferentes Tratamentos de Têmpera e Revenido. Rio de Janeiro, 2006. 106 p. Dissertação de Mestrado - Departamento de Ciência dos Materiais e Metalurgia, Pontifícia Universidade Católica do Rio de Janeiro.

Os aços de alta resistência e baixa liga (ARBL) pertencem a uma classe de aços que desperta o interesse de pesquisadores da área metal-mecânica. A pesquisa teve como objetivos estudar a influência dos tratamentos térmicos de têmpera e revenido sobre as propriedades do aço SAE 4140 e avaliar o comportamento do aço SAE 4140 quando submetido ao revenido na faixa de temperatura característica da fragilização. Inicialmente, o material foi tratado termicamente sob diferentes condições de têmpera e revenido. Após a usinagem dos corpos de prova, foram realizados ensaios de tração e energia ao impacto, bem como caracterizações microestruturais e fractográficas. Os resultados mostraram que as propriedades mecânicas do aço SAE 4140 foram influenciadas pelos parâmetros de revenido, em particular temperatura, além do tempo de permanência no forno antes do resfriamento.

\section{Palavras-Chave:}

Energia de impacto; fragilização no revenido; microestrutura. 


\section{ABSTRACT}

Ribeiro, Luis Paulo Pires Gonçalves. Caractherization of Mechanical Properties on SAE 4140 Steel after Different Treatments of Quenching and Tempering. Rio de Janeiro, 2006. 106 p. Master Dissertation - Department of Materials Science and Metallurgy, Pontifical Catholic University of Rio de Janeiro.

The high strength and low alloy steels (HSLA) belong to a class of steels in which researchers of the metal-mechanic area have particular interest. The aim of this work is to verify the influence of quenching and tempering heat treatments on the properties of the SAE 4140 steel as well as to evaluate its behaviour when subjected to tempering in a temperature range associated with the material's embrittlement. At first, the material was heat treated according with different quenching and tempering conditions. In the sequence, specimens machined from the treated material were subjected to tensile and impact energy tests and characterized by microstructural and fractographic analysis. The results showed that the mechanical properties of the material were influenced by the tempering parameters, specially temperature and time of treatment as well as the permanence time of the specimens in the furnace before cooling.

\section{Key-words}

Impact energy; tempering embrittlement ; microstructure. 


\section{Sumário}

$\begin{array}{ll}1 \text { INTRODUÇÃO } & 17\end{array}$

2 REVISÃO BIBLIOGRÁFICA 19

2.1. Microestrutura 22

2.1.1. O Papel dos Elementos de Liga 24

2.2 Fragilização no Revenido 25

2.2.1 Mecanismos de Ativação $\quad 27$

2.3 Fragilização da Martensita Revenida 28

2.3.1 Mecanismos de Ativação 28

2.4 Inclusões Não-Metálicas $\quad 31$

2.4.1 Tipos de Inclusões 33

2.4.1.1 Inclusões Exógenas $\quad 35$

2.4.1.2 Inclusões Endógenas $\quad 36$

2.4.1.2.1 Formação 37

2.4.1.2.2 Crescimento-Tamanho, Quantidade e Distribuição 38

2.4.1.2.3 Eliminação $\quad 39$

2.4.2 Influência das Inclusões nas Propriedades Mecânicas dos Aços

3 MATERIAL E PROCEDIMENTO EXPERIMENTAL 42

3.1. Material 42

3.2. Corte de Amostras 43

3.3. Tratamentos Térmicos 44

3.4 Posição de Retirada e Geometria dos Corpos de Prova das Amostras $\quad 47$

3.5 Ensaio de Tração 49

3.6 Ensaio de Impacto $\quad 49$

3.7 Medição de Microdureza 52

3.8 Caracterização Microestrutural 52

3.9 Caracterização Fractográfica 53 
4 APRESENTAÇÃO E DISCUSSÃO DOS RESULTADOS 54

4.1. Propriedades Mecânicas 54

4.1.1. Ensaio de Tração 54

4.1.2. Ensaio de Impacto 57

4.2. Microdureza 62

4.3 Caracterização Microestrutural 64

4.4 Caracterização Fractográfica 90

4.5 Considerações Finais 99

5 CONCLUSÕES 101

6 REFERÊNCIAS BIBLIOGRÁFICAS 102 


\section{Lista de figuras}

Figura 2.1 - Variação das propriedade mecânicas com o refino do tamanho de grão para os aços ARBL

Figura 2.2 - Efeito da exposição na faixa de temperatura de 450 a $500^{\circ} \mathrm{C}$ de fragilização no revenido em aços Cr-Ni comerciais e de alta pureza. $\quad 26$

Figura 2.3 - Influência do fósforo e antimônio na energia de impacto em função da temperatura de revenido de um aço $1 \frac{1}{2} \% \mathrm{Ni}-\mathrm{Cr}$-Mo. 30

Figura 3.1 - Variação de temperatura do forno com a porta aberta. $\quad 44$

Figura 3.2 - Variação de temperatura do forno com a porta fechada. $\quad 44$

Figura 3.2 - Posição de retirada de corpos de prova das amostras. $\quad 47$

Figura 3.4 - Geometria do corpo de prova de tração. 48

Figura 3.5 - Geometria do corpo de prova Charpy. 48

Figura 3.6 - Desenho da máquina de impacto Charpy. 50

Figura 3.7 - Posição do corpo de prova Charpy. 51

Figura 4.1 - Energia de impacto em função do tempo de revenido. $\quad 59$

Figura 4.2- Energia de impacto em função da temperatura para a condição aberta.

Figura 4.3 - Energia de impacto em função da temperatura para a condição fechada.

Figura 4.4 - Energia de impacto em função da temperatura de revenido.

Figura 4.5 - Microestrutura característica do aço SAE 4140 após tratamentos térmicos de têmpera e revenido na condição 1.Aumento de 100x.

Figura 4.6 - Idem figura anterior. Presença de traços de bainita (áreas mais claras). Aumento de 500x.

Figura 4.7 - Microestrutura característica do aço SAE 4140 após tratamentos térmicos de têmpera e revenido na condição 2.Aumento de 100x.

66

Figura 4.8 - Idem figura anterior. Presença de martensita revenida. Aumento de $500 x$.

Figura 4.9 - Microestrutura característica do aço SAE 4140 após tratamentos térmicos de têmpera e revenido na condição 3.Aumento de 100x.

Figura 4.10 - Idem figura anterior. Presença de martensita revenida (áreas mais escuras) e traços de bainita. Aumento de 500x. 
Figura 4.11 - Microestrutura característica do aço SAE 4140 após tratamentos térmicos de têmpera e revenido na condição 4.Aumento de 100x.

68

Figura 4.12 - Idem figura anterior. Presença de martensita revenida (áreas mais escuras). Aumento de 500x.

Figura 4.13 - Microestrutura característica do aço SAE 4140 após tratamentos térmicos de têmpera e revenido na condição 5.Aumento de 100x.

Figura 4.14 - Idem figura anterior. Presença de martensita revenida. Aumento de $500 x$.

Figura 4.15 - Microestrutura característica do aço SAE 4140 após tratamentos térmicos de têmpera e revenido na condição 6.Aumento de 100x. $\quad 70$

Figura 4.16 - Idem figura anterior. Presença de martensita revenida e traços de bainita (áreas mais claras). Aumento de 500x.

Figura 4.17 - Microestrutura característica do aço SAE 4140 após tratamentos térmicos de têmpera e revenido na condição 7.Aumento de 100x.

71

Figura 4.18 - Idem figura anterior. Presença de martensita revenida (áreas mais escuras) e traços de bainita. Aumento de 500x.

Figura 4.19 - Microestrutura característica do aço SAE 4140 após tratamentos térmicos de têmpera e revenido na condição 8 . Aumento de 100x.

Figura 4.20 - Idem figura anterior. Presença de martensita revenida (áreas mais escuras). Aumento de 500x.

Figura 4.21 - Microestrutura característica do aço SAE 4140 após tratamentos térmicos de têmpera e revenido na condição 9. Aumento de 100x. 73

Figura 4.22 - Idem figura anterior. Presença de traços de bainita. Aumento de $500 x$.

Figura 4.23 - Microestrutura característica do aço SAE 4140 após tratamentos térmicos de têmpera e revenido na condição 10. Aumento de 100x. 74

Figura 4.24 - Idem figura anterior. Presença de martensita revenida e traços de bainita (áreas mais claras). Aumento de 500x.

Figura 4.25 - Microestrutura característica do aço SAE 4140 após tratamentos térmicos de têmpera e revenido na condição 11. Aumento de 100x. 75 Figura 4.26 - Idem figura anterior. Presença de martensita revenida (áreas mais escuras). Aumento de 500x.

Figura 4.27 - Microestrutura característica do aço SAE 4140 após tratamentos térmicos de têmpera e revenido na condição 12. Aumento de 100x. 
Figura 4.28 - Idem figura anterior. Presença de martensita revenida e traços de bainita (áreas mais claras). Aumento de 500x.

Figura 4.29 - Microestrutura característica do aço SAE 4140 após tratamentos térmicos de têmpera e revenido na condição 13. Aumento de 100x.

Figura 4.30 - Idem figura anterior. Presença de martensita revenida (áreas mais escuras). Aumento de 500x.

Figura 4.31 - Microestrutura característica do aço SAE 4140 após tratamentos térmicos de têmpera e revenido na condição 14. Aumento de 100x.

78

Figura 4.32 - Idem figura anterior. Presença de traços de bainita (áreas mais claras). Aumento de 500x.

78

Figura 4.33 - Microestrutura característica do aço SAE 4140 após tratamentos térmicos de têmpera e revenido na condição 15. Aumento de 100x.

79

Figura 4.34 - Idem figura anterior. Presença de martensita revenida (áreas mais escuras). Aumento de 500x.

Figura 4.35 - Microestrutura característica do aço SAE 4140 após tratamentos térmicos de têmpera e revenido na condição 16. Aumento de 100x.

80

Figura 4.36 - Idem figura anterior. Presença de martensita (áreas mais escuras). Aumento de 500x.

80

Figura 4.37 - Microestrutura característica do aço SAE 4140 após tratamentos térmicos de têmpera e revenido na condição 17. Aumento de 100x.

Figura 4.38 - Idem figura anterior. Presença de martensita revenida (áreas mais escuras). Aumento de 500x.

Figura 4.39 - Microestrutura característica do aço SAE 4140 após tratamentos térmicos de têmpera e revenido na condição 18. Aumento de 100x.

Figura 4.40 - Idem figura anterior. Presença de martensita revenida e traços de bainita (áreas mais claras). Aumento de 500x.

Figura 4.41 - Microestrutura característica do aço SAE 4140 após tratamentos térmicos de têmpera e revenido na condição 19. Aumento de 100x.

83

Figura 4.42 - Idem figura anterior. Presença de martensita revenida (áreas mais escuras). Aumento de 500x.

Figura 4.43- Microestrutura característica do aço SAE 4140 após tratamentos térmicos de têmpera e revenido na condição 20. Aumento de 100x. 
Figura 4.44 - Idem figura anterior. Presença de martensita revenida e bainita (áreas mais claras). Aumento de 500x.

Figura 4.45 - Microestrutura característica do aço SAE 4140 após tratamentos térmicos de têmpera e revenido na condição 21. Aumento de 100x.

Figura 4.46 - Idem figura anterior. Presença de martensita revenida e bainita (áreas mais claras). Aumento de 500x.

Figura 4.47 - Microestrutura característica do aço SAE 4140 após tratamentos térmicos de têmpera e revenido na condição 22. Aumento de 100x.

86

Figura 4.48 - Idem figura anterior. Presença de martensita revenida (áreas mais escuras). Aumento de 500x.

Figura 4.49 - Microestrutura característica do aço SAE 4140 após tratamentos térmicos de têmpera e revenido na condição 23. Aumento de 100x.

Figura 4.50 - Idem figura anterior. Presença de martensita revenida e traços de bainita (áreas mais claras). Aumento de 500x.

Figura 4.51 - Microestrutura característica do aço SAE 4140 após tratamentos térmicos de têmpera e revenido na condição 24. Aumento de 100x.

Figura 4.52 - Idem figura anterior. Presença de martensita (áreas mais escuras). Aumento de 500x.

Figura 4.53 - Microestrutura característica do aço SAE 4140 após tratamentos térmicos de têmpera e revenido na condição 25. Aumento de 100x.

Figura 4.54 - Idem figura anterior. Presença de martensita (áreas mais escuras). Aumento de 500x.

Figura 4.55 -Superfície de fratura da condição 8. Aumento de 2000x. 90

Figura 4.56-Idem figura anterior.Aumento de 3000x.

Figura 4.57 - Superfície de fratura da condição 16. Aumento de 2000x. 91

Figura 4.58 - Idem figura anterior. Aumento de 3000x.

Figura 4.59- Superfície de fratura da condição 19. Aumento de 2000x. 92

Figura 4.60 - Idem figura anterior. Aumento de 3000x.

Figura 4.61 - Superfície de fratura da condição 20. Aumento de 2000x. 93

Figura 4.62 - Idem figura anterior. Aumento de 3000x. 94

Figura 4.63 - Superfície de fratura da condição 21. Aumento de 2000x. 95

Figura 4.64 - Idem figura anterior.Aumento de 3000x. 95

Figura 4.65 - Superfície de fratura da condição 22. Aumento de 2000x. 96

Figura 4.66 - Idem figura anterior. Aumento de 3000x. 96 
Figura 4.67- Superfície de fratura da condição 23. Aumento de 2000x. 97

Figura 4.68 - Idem figura anterior. Aumento de 3000x. 97

Figura 4.69-Superfície de fratura da condição 24. Aumento de 2000x. 98

Figura 4.70- Idem figura anterior. Aumento de 3000x. 98 


\section{Lista de tabelas}

Tabela 2.1 - Fontes de Inclusões. 34

Tabela 3.1 - Composição Química do material (\% em peso) 42

Tabela 3.2 - Quadro Resumo dos Diferentes Tratamentos Térmicos Adotados.

Tabela 3.3 - Parâmetros adotados no ensaio de tração. 49

Tabela 3.4 - Parâmetros adotados no ensaio de impacto. 52

Tabela 4.1 - Propriedades Mecânicas do aço SAE 4140.

Tabela 4.2 - Resultados de ensaio de impacto do aço SAE 4140. 58

Tabela 4.3 - Resultados de microdureza do aço SAE 4140. 